\title{
Intercultural Attitudes as Predictors of Student's Prejudices Towards Refugees
}

\author{
Petia Genkova $^{1}$ (D) Anna Groesdonk ${ }^{1}$
}

Accepted: 3 July 2021 / Published online: 23 July 2021

(C) The Author(s) 2021

\begin{abstract}
One of the major challenges for modern western societies is the reduction of prejudice in order to achieve a sufficient level of integration of immigrants and especially refugees. The current literature thus presents a multitude of approaches to understand and reduce prejudices. Therefore, the following paper investigates the relationships between ethnic identity, acculturation attitudes, intercultural competence, and prejudice and how contact experiences shape these relationships for students in Germany with and without migration background. The results show that there is a significant relationship between prejudice and the social identity, cultural intelligence, and acculturation strategies. Furthermore, the results indicate that the experienced contact quality and quantity to refugees moderate the effect of acculturation strategies on overt prejudice and xenophobia. However, the relationship between acculturation strategies and covert prejudice is only moderated by contact quantity. Because of the relatively weak manifestations of the dependent variables in the study at hand, alternative instruments should be used for investigation. Based on the obtained results, this paper finally tries to give some guidance for the facilitation of diversity and reduction of prejudice at higher education institutions.
\end{abstract}

Keywords Integration - Refugees · Cultural intelligence $\cdot$ Acculturation strategies · Ethnic identity $\cdot$ Prejudice

In recent years, one topic dominated news headlines: migration. A vast amount of people is fleeing from war and conflict. Accordingly, the integration of newly arrived refugees proves to be one of the greatest challenges for western societies. According to Wessendorf and Phillimore (2019), integration describes the socio-economic, political, social, and cultural adaption of new-comers, as well as the adaption of the

Petia Genkova

P.Genkova@hs-osnabrueck.de

Anna Groesdonk

Anna.Groesdonk@hs-osnabrueck.de

1 Osnabrück University of Applied Sciences, 49076 Osnabrück, Germany 
established population to the new arrivals (Wesselmann \& Phillimore, 2019). In this study, we consider those individuals as migrants, which immigrated to Germany or whose parents immigrated to Germany, according to Kemper's (2010) reasonable definition. After a history of migration, a variety of populations with different cultural backgrounds is living in Germany as a part of the German society. At the same time, research confirms that with increasing social and cultural diversity, prejudices between social groups increase as well (Hendriks \& Burger, 2020). Prejudices are affective, negative attitudes towards a person based on their perceived group membership. They can lead to negative, discriminatory behavior towards the respective outgroup. Based on a lack of information, prejudices, however, cannot be removed by easily providing sufficient information (Aronson et al., 2008). Many EU citizens, with substantial variations between countries, perceive threats to their jobs and believe that refugees waste more financial resources than they generate. As a consequence, prejudices towards refugees cause negative intergroup behavior such as discrimination, which is one of the reasons for decreased life satisfaction of migrants in Europe (European Social Survey, 2014). It becomes clear that for successful integration, prejudices towards refugees need to be removed or at least reduced in European societies. Therefore, this study aims to identify and/or confirm factors, which relate to prejudices. Considering the importance of refugee integration in these days, we focus on attitudes of German students with and without migration background towards refugees. Whereas past generations of immigrants struggled to participate in the German society, the attitude of future generations is of high interest, to reveal substantial problems for the integration of migrants and especially refugees in the future. We raised the following research questions: How can different types of prejudices against refugees and xenophobia be predicted? Constructs of social identity, cultural intelligence, and acculturation strategies as well as the influence of contact with refugees will be scrutinized.

\section{Prejudices and Social Identity}

How we perceive others depends on how we see ourselves and how we categorize ourselves. In this context, identity plays a major role. Identity is a multi-layered and highly debated concept, which relates to the feeling of who we are and to who we belong to (Hall, 2003). Identity thus comprises the personal identity, which separates us from other individuals, and the social identity. The latter influences the self-concept through the feeling of belonging to social groups. Members of those groups are cognitively represented by stereotypes of certain common traits (Simon $\&$ Trötschel, 2007). The membership in social groups contributes to the satisfaction of important human needs, like positive self-evaluation as well as belongingness and safety (Pratt, 2001). According to Tajfel and Turner (1986), mere categorization of the self and others into groups can be responsible for ingroup favoritism. Social groups imply both, being more similar to ingroup members and differentiate oneself from outgroup members. Thus, a strong sense of collective belonging increases the tendency to exclude individuals who do not fit in. 
Often, social identity is mentioned along with ethnic identity, which is said to be a derivate of the former concept. Schwartz et al. (2006) thus describe ethnic identity as the subjective meaning of one's own ethnic sense of belonging and the feelings one has towards this group. Importantly, those feelings can be different from an individual's actual ethnicity (Schwartz et al., 2006). Considering the above, strong ethnic identity might lead to negative attitudes and behaviors against members of other ethnic groups. Correspondingly, Verkuyten and Zaremba (2005) demonstrated a connection between right-wing populist movements and higher identification with the ethnic ingroup along with the simultaneous devaluation of other societal groups. Moreover, a variety of studies demonstrated the relationship between social identity, ethnic identity respectively, and prejudices towards migrants not only for right-wing extremists but as a general phenomenon (Badea et al., 2018; Pettigrew \& Meertens, 1995). Especially refugees are often perceived as a threat towards the ingroup, either as a symbolic threat through their foreign values, beliefs, or morals or as a realistic threat in terms of economic resources or political power (Stephan et al., 2000). Transferring this to group differences between German host country nationals and refugees in Germany, ingroup/outgroup thinking is most likely to occur, depending on the individual level of identification with the ingroup and individual values (Lynch \& Kalaitzake, 2020).

Just as the reasons for prejudices vary, there are different expressions of prejudices. Pettigrew and Meertens (1995) took a more differentiated look at the concept of prejudices. They developed a theory which differentiates between covert and overt prejudices. Whereas overt prejudices are direct and can be articulated, covert prejudices are defined as indirect negative attitudes towards the outgroup. Prejudices are not a matter of pathological attitudes, and they do not necessarily lead to negative consequences (Dovidio et al., 2010). Pettigrew and Meertens (1995) focus on the cognitive aspects of prejudices. In order to consider more extreme forms of prejudice as well, we took the more common concept of xenophobia into account. While xenophobia is seen as an extended version of prejudice, it is characterized by fear against members of the outgroup, regarding a variety of possible issues of threat and by aggression against the outgroup (Williams, 2010).

With his work The Nature of Prejudice (1954), Allport was one of the first researchers who saw the contact between different ethnic groups as a chance to reduce prejudice (Aronson et al., 2008). In addition to the equal status of distinct groups, according to Allport (1954), the same goals need to be followed, in a situation characterized by cooperative instead of competitive goal interdependence. Finally, the support of authorities is also required. For instance, Pettigrew and Tropp (2006) found in a comprehensive meta-analysis that enhanced contact between groups is indeed related to the reduction of prejudices. Yet, it was found that not all of Allport's four conditions have to be present. Indeed, the conditions facilitate the reduction of prejudices, yet they need to be seen as an interconnected package that allows for missing parts rather than indispensable supporting pillars. 


\section{Acculturation}

Acculturation is defined by the change of cultural patterns of groups of individuals, which is caused by the persistent and direct contact with different cultures (Berry \& Sam, 1997). Such changes can happen either one-sided or bilateral between both groups. Talking about acculturation, individuals differ in two regards. On the one hand, individuals differ in whether they strive to maintain their own cultural background or not. On the other hand, there are differences in how far individuals want to have contact with members of the other culture. Berry and Sam (1997) derive four behavioral patterns: assimilation, separation/segregation, integration, and marginalization.

Assimilation describes an individual who abandons his/her own culture/cultural customs in favor of the other culture. Often, those individuals search contact with a dominant culture in society while avoiding the maintenance of their original identity. Separation defines the opposite behavior. Group members avoid the contact with the other group and decline the other culture. In contrast, own customs are highly valued. When this behavior is favored by the dominant culture, there is talk of segregation (van Dick et al., 1997). Integration is commonly known under the term of biculturalism (Schwartz et al., 2006). Hereby, individuals try to maintain their original identity, whereas they search for contact with the dominant community. Finally, such individuals, who lost a sense of belonging to either of the groups are forced into marginalization. These people feel alienated by both cultures. They renounce their original culture, and it is not possible for them to adapt to the new culture. However, this type of acculturation is seldom found according to Berry and Sam (1997), even though it might be caused by experiences of discrimination or exclusion (Berry \& Sam, 1997). The different types of acculturation strategies can be understood as behavioral intentions to engage with other cultures and are probably closely related to positive attitudes and negative attitudes such as prejudices. Considering this, van Dick et al. (1997) showed comprehensively that the four acculturation strategies represent a unidimensional construct. Consequently, having a positive acculturation strategy means to have a strong integration strategy and low expressions of both separation and assimilation. In this study, we tested acculturation strategies for their value as predictors of prejudice. Of course, the relationships between a certain attitude and prejudices depend on context variables. We assumed that the context of previous experiences with the outgroup shapes the way acculturation strategies influence prejudices. Moreover, the degree to which someone is able to interact with members of another culture should relate to prejudices as well.

\section{Intercultural Competence}

With the growing globalization and internationalization of economic sectors in the past years, the interest for the construct of intercultural competence highly increased. A common definition describes intercultural competence as the "ability, based on one's own intercultural knowledge, as well as the skills and attitudes to successfully and appropriately interact with individuals and groups from other 
cultures" (Deardorff, 2006 p. 247f.). The heterogeneity of the approaches to intercultural competence causes a multitude of measurement instruments, trying to describe and assess relevant characteristics. One of the most valid concepts is cultural intelligence, which is often displayed by structural models describing the systematic applicability of four subcomponents. Metacognitive cultural intelligence is the cultural consciousness and awareness of an individual in the context of intercultural interactions. The cognitive cultural intelligence describes the cultural knowledge of a person regarding norms, customs, and conventions in different intercultural situations. Motivational cultural intelligence describes the ability to direct one's attention and energy on cultural differences and to confront oneself with them. Finally, behavioral cultural intelligence denotes the ability of a person to show appropriate verbal and nonverbal behavior during interaction with individuals from different cultural backgrounds (van Dyne, Ang \& Koh 2008).

\section{The Current Study}

As an overarching goal, this research aims at building upon the current research literature and identifying factors which influence prejudices towards refugees. In more detail, the research question is formulated as how can different types of prejudices against refugees and xenophobia be predicted?

In general, respective influences of social identity, ethnic identity, cultural intelligence, and acculturation strategies serve as predictors, shedding light on how to predict prejudice. As described in the rationale, the perception of the outgroup is influenced by the identification with and definition of the ingroup. The degree to which individuals integrate the group in their self-concept contributes to differences in interpreting experiences in the social world (Pettigrew \& Tropp, 2006). The concept of social identity indicates that identity forms by separating one's own group from others and that this can lead to a strongly developed ingroup favoritism and even hostility towards the outgroup. Following this, we predicted a relationship between the ethnic identity and all expressions of prejudices. Consequently, hypothesis 1 was formulated:

H1: The identification with the ingroup has a positive relationship with overt and covert prejudices towards refugees and the manifestation of xenophobia.

Research on the contact hypothesis provides evidence that frequent and qualitatively high contact (positive experiences) with people from different cultures and ethnicities can reduce prejudices and therefore improve intercultural communication (Allport, 1954; Miles \& Crisp, 2014). Hence, it was suspected that both contact quantity and contact quality would have a moderating effect on the influence of the independent variables on prejudices. Thus, $\mathrm{H} 2$ is derived:

$\mathrm{H} 2$ : The relationship between the investigated independent variables and the prejudices against refugees is moderated by the contact with refugees. Contact quality and contact quantity are independent moderators. 
Reviewing research on intercultural contact, it becomes apparent that either learned and/or inborn ways to respond to the environment play a crucial role in judging/misjudging others (Earley \& Mosakowski, 2004). Thereby, the ability to effectively deal with new situations and new environments also greatly determines the perception of one's surroundings and with it the perception of other individuals. Hasty, negative, and flawed judgment of others, in form of prejudices, might follow from a lack of skill to deal with foreigners, such as refugees in particular. The social identity, cultural intelligence, and acculturation strategies comprise a set of characteristics and skills, which help the individual to navigate through unknown social settings, inevitably caused by intercultural interaction. We expected that these factors predict attitudes towards refugees. This goes for migrants and natives alike. Therefore, $\mathrm{H} 3$ is given:

H3: The degree of ethnic identity relates positively, while cultural intelligence and acculturation strategies relate negatively to overt and covert prejudices along with xenophobia.

\section{Methods}

\section{Design and Procedure}

We conducted a cross-sectional online study on students in Germany from May 2018 to July 2019. The survey was distributed through various social media formats, such as Facebook. Participants easily followed a link to the survey website and confirmed to be at least 18 years old and to study at a German university. We did not offer incentives.

\section{Measurement Tools}

We used the multigroup ethnic identity measure (MEIM) (Phinney, 1992) to assess the ethnic identity. Fourteen 5-point Likert scale items measure the ethnic identity with subscales for affirmation and belonging (confirmation and belonging). Answering options were adjusted for Germans and respectively for migrants living in Germany. (1) I see myself as German; (2) I see myself as a migrant; (3) I see myself as an ethnic German immigrant to Germany; and (4) open answer.

To assess cultural intelligence, the cultural intelligence scale (Van Dyne et al., 2008) was chosen. This scale measures the metacognitive, cognitive, motivational, and behavioral dimension of cultural intelligence, with a total of 20 items and a 7-point Likert scale as the response format.

For assessing the contact with refugees, the general intergroup contact quantity and contact quality scale (von Islam \& Hewstone, 1993) was chosen. This scale is divided into contact quantity and contact quality, which are measured by five items, respectively. Whereas the contact quantity measures the frequency of contact 
in different settings, the contact quality is assessed by asking if the encounter was experienced as positive or negative.

In order to measure prejudices towards the group of refugees, the blatant and subtle prejudice scale (Pettigrew \& Meertens, 1995) was in use. Since covert prejudices have been on the rise in many European countries for many years and replace the overt prejudices to an increasing extent, Pettigrew and Meertens (1995) developed this scale to close this empirical gap. The scale comprises 20 items of which one half measures overt prejudices and the other half measures covert prejudices. Overt prejudices were operationalized as threat and rejection as well as low familiarity. Covert prejudices were constituted by the sub-dimensions of defense of traditional values and exaggeration of cultural differences as well as denial of positive emotions.

To assess xenophobia, the short version of the eponymous scale xenophobia was chosen (Wetzels, Gabriel \& Pfeiffer 1998). This scale entails nine items, to which can be responded on a 4-point Likert scale. The internal consistency was calculated in the form of Cronbach's alpha for three different target groups, i.e., resettlers, migrants, and native Germans. Values of $\alpha=0.62, \alpha=0.55$, and $\alpha=0.83$ were obtained. In order to specifically measure xenophobia, this shortened scale was included in the research.

The survey acculturation strategy scale (van Dick et al., 1997) was developed to measure acculturation attitudes in the German-speaking region and divides acculturation in integration, assimilation, and segregation. Using 13 6-point Likert scale items, a unidimensional factor structure representing a global attitude to a multicultural society was assessed. Therefore, integration is compared to assimilation and segregation. We obtained an internal consistency of $\alpha=0.84$.

\section{Participants}

In total, 699 students completed the survey. With 69.8\%, two thirds of the student sample were female, whereas $30.2 \%$ identified as male. The average age was 25.68 years $(\mathrm{SD}=4.61)$, while the range between the youngest (16 years) and the oldest (50 years) was quite big. $89.9 \%$ were born in Germany and $10.1 \%$ in a foreign country. $19.1 \%$ of the participants stated to have a migration background. This self-indication was used as a categorization criterion for "students without migration background" and "students with migration background." As first-generation immigrants who immigrated as children are likely to experience the exact same conditions as second-generation migrants and studies report similar attitudes and problems of acculturation for first- and second-generation migrants depending on age and on how long they and their parents have been staying in a certain country, we decided not to differentiate between first- and second-generation migrants. Twentysix percent of the students studied subjects related to education, 22\% STEM subjects (excluding science education students), 18\% business subjects, 17\% psychology or related fields, $12 \%$ medicine or related fields like physiotherapy, and $5 \%$ arts or music. Around two thirds $(67 \%)$ of the sample were bachelor students, while one third was in a master's program. 


\section{Results}

Table 1 displays the descriptive statistics as well as the Cronbach's alpha values for internal consistency. To test hypothesis 1 (that the ethnic identification with the ingroup predicts overt and covert prejudices towards refugees and the manifestation of xenophobia), we used regression analyses. Statistical preconditions were fulfilled sufficiently. Our results evince that the degree of identification with the ethnic ingroup strongly predicts the overt prejudices for the group without migration background (standardized regression coefficient $\beta=0.70$, $p<0.01)$. There was no significant relationship for the participants with migration background.

For participants without migration background, identification with the ethnic ingroup was a strong predictor for covert prejudices $(\beta=0.54, p<0.01)$ as well. The relationship for participants with migration background $(\beta=0.28, p<0.05)$ is weaker yet exists. These results support the claim that the stronger identification with the ingroup increases covert prejudices, regardless of group membership. Thus, H1 can be seen as partly confirmed:

$\mathrm{H} 2$ : The relationship between the investigated independent variables and the prejudices against refugees is moderated by the contact with refugees. Contact quality and contact quantity are independent moderators.

To test hypothesis 2 (that the relationship between the investigated independent variables and the prejudices against refugees is moderated by the contact quantity and quality), a moderated mediation analysis was performed, using the macro PROCESS, version 3.1 by Hayes and Cai (2007). As stated earlier, it was expected that the mentioned independent variables influence prejudices. However, they also might have effects on each other, therefore distorting the direct effects on prejudices. Based on this, 36 possible combinations of dependency among the factors were produced. Of those 36 tested models, only seven have been proven significant. In this section, only the significant combinations are presented. Hence, $\mathrm{H} 2$ can only be partly confirmed.

Five out of six models concerning the combination of the independent variable acculturation strategy, the moderators contact quality, and contact quantity as well as the three dependent variables with manifestations of prejudices (i.e., overt and covert prejudices and xenophobia) were significant with $p<0.01$. An overview of the combinations is provided in Table 1. It was demonstrated that there is an interaction effect of acculturation strategy and the contact quantity predicting overt prejudices. Fifty-five percent of the total variance could be explained, which is significant with $p<0.01$. The interaction effect with $p<0.01$ is highly significant as well. The same applies to covert prejudices as the criterion. The explained variance of this model is at $41 \%$ and with $p<0.01$ highly significant. The interaction effect with $p=0.02$ is significant, $p<0.05$. Finally, the combination of contact with manifestation of xenophobia was tested. Again, the model shows to be significant with $p<0.01$ and can explain $45 \%$ of the variance. Surprisingly, contact quantity had no 
Table 1 Descriptive Statistics and bivariate correlations

\begin{tabular}{lllllll}
\hline & & Min & $\operatorname{Max}$ & $M$ & $S D$ & $\alpha$ \\
\hline 1 & Contact quantity & 1.00 & 6.80 & 2.20 & 1.16 & 0.79 \\
2 & Contact quality & 1.00 & 6.80 & 4.33 & 1.33 & 0.83 \\
3 & Acculturation strategy & 1.00 & 5.85 & 4.09 & 0.98 & 0.89 \\
4 & Xenophobia & 1.00 & 3.78 & 1.68 & 0.52 & 0.87 \\
5 & Subtle prejudice & 1.00 & 4.00 & 2.51 & 0.58 & 0.84 \\
6 & Blatant prejudice & 1.00 & 4.00 & 1.71 & 0.63 & 0.83 \\
7 & Intercultural intelligence & 2.48 & 4.30 & 3.34 & 0.34 & 0.89 \\
8 & Ethnic identity & 2.20 & 3.20 & 2.65 & 0.28 & 0.84 \\
\hline
\end{tabular}

significant direct effect on xenophobia, $p=0.10$. On the other hand, the interaction effect between contact quantity and acculturation strategy on xenophobia is significant with $p<0.03$. This implies that intergroup contact quantity only leads to less xenophobia under the condition of a positive attitude towards this interaction.

The moderation effect of contact quantity and covert prejudices is displayed in Fig. 1. High values for contact quality and quantity are those above the sample average; values underneath the sample average are considered as low values. When the moderation variable is replaced by contact quality, significant interaction effects for acculturation strategies can be confirmed as well. In relationship to overt prejudices, the model explains $65 \%$ of the variance and is significant with $p<0.01$. The interaction effect between acculturation strategy and contact quality on overt prejudices is also significant with $p<0.01$. For the sake of completeness, the insignificant interaction effect of contact quality and acculturation strategy on covert prejudice should be mentioned. With $p=0.11$, this was found to be not significant, wherefore no

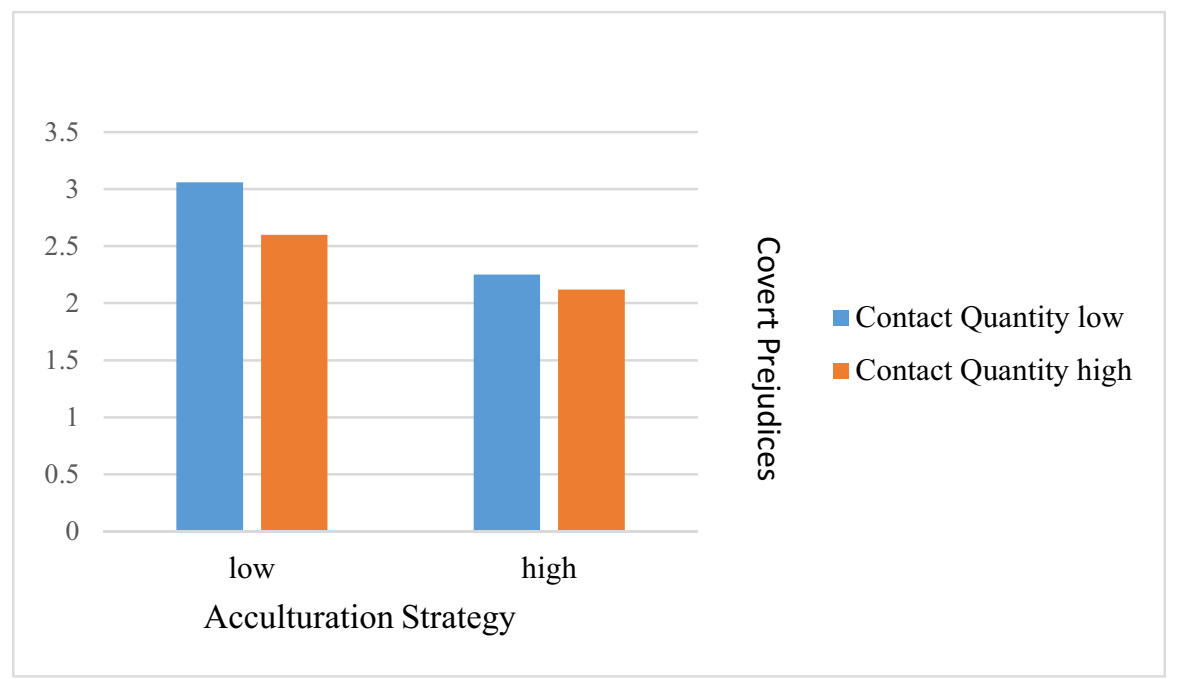

Fig. 1 Influence of contact quantity on the relationship between acculturation strategy and covert prejudices (own depiction) 
interaction effect is assumed. Regarding the criterion xenophobia, $p<0.01$ and an explained variance of $57 \%$ could be found. The interaction term is also $p<0.01$ and thus highly significant. An illustration of the influence of contact quality on the relationship between acculturation strategy and overt prejudices can be found in Fig. 2 . It seems that the effect of acculturation strategy on different subtypes of prejudice is moderated by contact quality and quantity.

Notion: Centralized mean predictors, standard error HC3-corrected.

Another predictor for which the interaction effect was found to be significant was the identification with the ingroup (social identity) of participants without migration background (Germans). For the variables social identity and prejudices, two models with the moderator variable contact quality could be confirmed. Concerning overt prejudices, the explained variance was $62 \%$. With $p<0.01$, the model is significant. Also, concerning the impact on the manifestation of xenophobia, a significant interaction effect with $p<0.01$ was obtained. In Fig. 3, the influence of contact quality on the relationship between identification of the ingroup for participants without migration background and overt prejudices is displayed as an example. An overview of the values can be found in Table 2. Quite similar results were obtained for possible interaction effects between social identity and contact quality and two subcomponents of the prejudice construct. For both overt prejudices and xenophobia, the statistical output is presented in Table 3.

In order to test hypothesis 3 (that the degrees of ethnic identity, cultural intelligence, and acculturation strategies relate to overt and covert prejudices along with xenophobia), we conducted multiple regression with HC3-corrected standard errors, using the heteroscedasticity-consistent standard error estimates of OLS regression (HCREG) of Hayes and Cai (2007). Statistical requirements were met (see Table 4). With a $\beta=0.15$ and $p=0.01$, the ethnic identity has a positive influence on overt

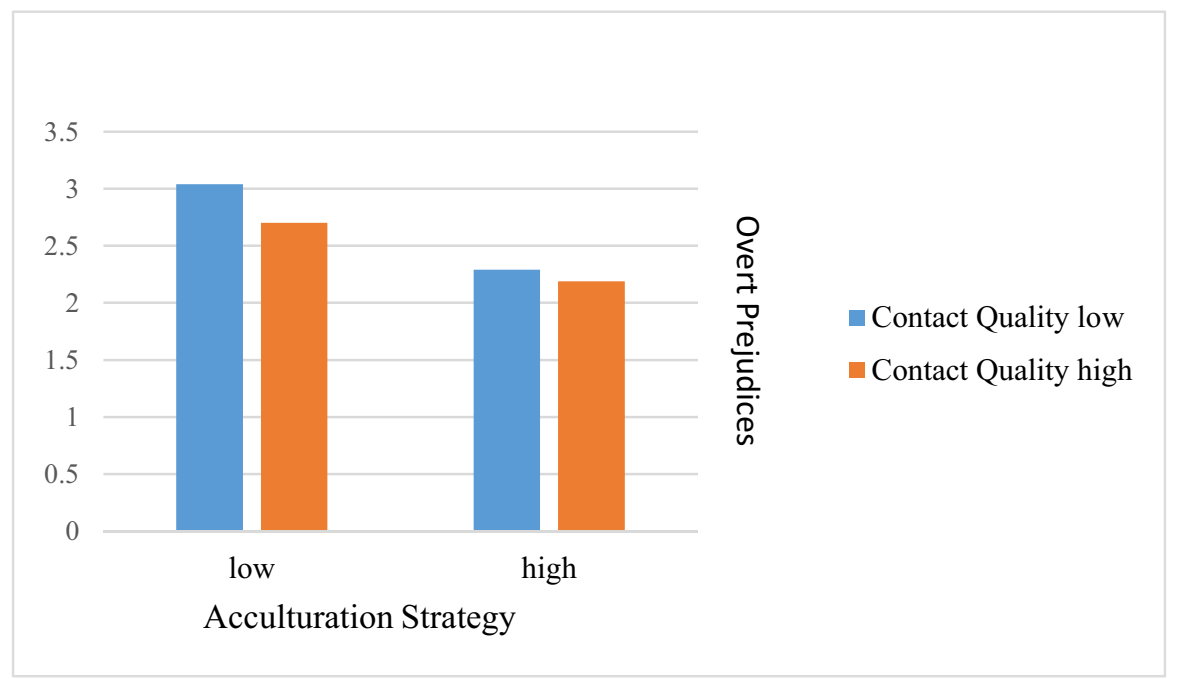

Fig. 2 Influence of contact quality on the relationship between acculturation strategy and overt prejudices (own depiction) 


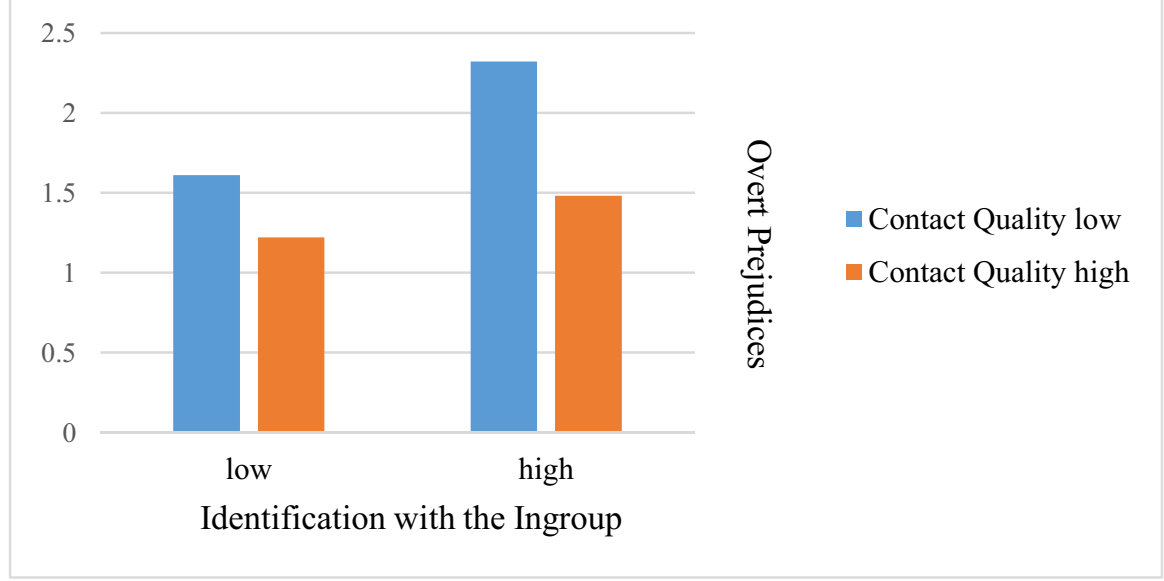

Fig. 3 Influence of contact quality on the relationship between identification with the ingroup (DE) and overt prejudices (own depiction)

prejudices. The influence of cultural intelligence $(\beta=-0.22$ and $p<0.01)$ as well as acculturation strategy value $(\beta=-0.36$ and $p<0.01)$ has a significant negative impact. Overall the model is significant with $p<0.01$ and explains $56 \%$ of the variance, supporting hypothesis 3 . The same model was tested for covert prejudices. Overall, the whole model was found to be significant with $p<0.01$ and had an explained variance of $41 \%$. Focusing on the individual predictors, it becomes visible

Table 2 Moderation analysis, predictor acculturation strategy

\begin{tabular}{|c|c|c|c|c|c|c|c|}
\hline \multirow[b]{2}{*}{$\mathrm{K}$} & & \multicolumn{3}{|c|}{ Coefficient } & \multicolumn{3}{|c|}{ Model } \\
\hline & & $\bar{\beta}$ & $\mathrm{SE}$ & $p$ & $\overline{R^{2}}$ & $F$ & $p$ \\
\hline \multirow[t]{6}{*}{ Overt } & Acculturation & -0.46 & 0.04 & $<0.001$ & 0.55 & 61.76 & $<0.001$ \\
\hline & Contact quantity & -0.09 & 0.03 & $<0.001$ & & & \\
\hline & Interaction & 0.11 & 0.03 & $<0.001$ & & & \\
\hline & Acculturation & -0.32 & 0.05 & $<0.001$ & 0.65 & 95.19 & $<0.001$ \\
\hline & Contact quality & -0.17 & 0.02 & $<0.001$ & & & \\
\hline & Interaction & 0.09 & 0.02 & $<0.001$ & & & \\
\hline \multirow[t]{3}{*}{ Covert } & Acculturation & -0.33 & 0.04 & $<0.001$ & 0.41 & 29.15 & $<0.001$ \\
\hline & Contact quantity & -0.13 & 0.03 & $<0.001$ & & & \\
\hline & Interaction & 0.07 & 0.03 & 0.02 & & & \\
\hline \multirow[t]{6}{*}{ Xeno } & Acculturation & -0.35 & 0.05 & $<0.001$ & 0.45 & 25.62 & $<0.001$ \\
\hline & Contact quantity & -0.04 & 0.03 & 0.10 & & & \\
\hline & Interaction & 0.07 & 0.03 & 0.03 & & & \\
\hline & Acculturation & -0.25 & 0.04 & $<0.001$ & 0.57 & 60.04 & $<0.001$ \\
\hline & Contact quality & -0.13 & 0.02 & $<0.001$ & & & \\
\hline & Interaction & 0.08 & 0.02 & $<0.001$ & & & \\
\hline
\end{tabular}


Table 3 Moderation analysis, predictor identification with the ingroup of participants without migration background

\begin{tabular}{|c|c|c|c|c|c|c|c|}
\hline \multirow[b]{2}{*}{$K$} & & \multicolumn{3}{|c|}{ Coefficient $>$} & \multicolumn{3}{|c|}{ Model } \\
\hline & & $\beta$ & SE & $p$ & $R^{2}$ & $F$ & $p$ \\
\hline \multirow[t]{3}{*}{ Overt } & Social identity (DE) & 0.17 & 0.02 & $<0.001$ & 0.62 & 77.16 & $<0.001$ \\
\hline & Contact quality & -0.24 & 0.03 & $<0.001$ & & & \\
\hline & Interaction & 0.06 & 0.02 & 0.01 & & & \\
\hline \multirow[t]{3}{*}{ Xeno } & Social identity (DE) & 0.14 & 0.02 & $<0.001$ & 0.60 & 61.79 & $<0.001$ \\
\hline & Contact quality & -0.19 & 0.03 & $<0.001$ & & & \\
\hline & Interaction & -0.05 & 0.01 & $<0.001$ & & & \\
\hline
\end{tabular}

Notion: Centralized mean predictors, standard error HC3-corrected.

that cultural intelligence with $\beta=-0.22$ and $p<0.01$ as well as acculturation strategies with $\beta=-0.26$ and $p<0.01$ negatively influences covert prejudices. However, the ethnic identity with $p=0.26$ is not significant.

Finally, the influence of the three independent variables on the manifestation of xenophobia was tested. Cultural intelligence $(\beta=-0.12$ and $p<0.05)$ and acculturation strategies $(\beta=-0.29$ and $p<0.05)$ showed a significant negative impact on xenophobia. Ethnic identity with $p=0.05$ was hovering above the significance level. It became evident that this construct was found to be significant in the regression analysis without the HC3-corrected standard error $(p=0.02)$. The whole model with $p<0.01$ is still significant, whereby $47 \%$ of the variance is explained, which gives reason to accept $\mathrm{H} 3$ with regard to xenophobia. Here, the impact of ethnic identity was also insignificant.

Table 4 Multiple regression, ethnic identity, cultural intelligence, acculturation

\begin{tabular}{|c|c|c|c|c|c|c|c|}
\hline \multirow[b]{2}{*}{$K$} & & \multicolumn{3}{|c|}{ Coefficient } & \multicolumn{3}{|c|}{ Model } \\
\hline & & $\beta$ & SE & $p$ & $R^{2}$ & $F$ & $p$ \\
\hline \multirow[t]{3}{*}{ Overt } & Ethnic identity & 0.15 & 0.06 & 0.01 & 0.56 & 62.06 & $<0.01$ \\
\hline & Cultural intelligence & -0.22 & 0.05 & $<0.01$ & & & \\
\hline & Acculturation & -0.36 & 0.06 & $<0.01$ & & & \\
\hline \multirow[t]{3}{*}{ Covert } & Ethnic identity & 0.07 & 0.07 & 0.26 & 0.41 & 41.20 & $<0.01$ \\
\hline & Cultural intelligence & -0.22 & 0.04 & $<0.01$ & & & \\
\hline & Acculturation & -0.26 & 0.06 & $<0.01$ & & & \\
\hline \multirow[t]{3}{*}{ Xeno } & Ethnic identity & 0.12 & 0.06 & 0.05 & 0.47 & 38.92 & $<0.01$ \\
\hline & Cultural intelligence & -0.13 & 0.04 & $<0.01$ & & & \\
\hline & Acculturation & -0.29 & 0.06 & $<0.01$ & & & \\
\hline
\end{tabular}

Notion: Standard error with HC3-corrected. 


\section{Interpretation}

First, it is to note that although significant relationships between prejudices and other factors were obtained in this study, the strength of those prejudices held by the participants appeared to be low. Evaluation of the scale shows that the identification of German participants with the German ethnicity is not strong. This suggests that many natives identify with the bigger group of Europeans and a more inclusive European identity is present. Accordingly, many participants stated that they are human or (German) European. Further research, especially enabling comparisons to different age groups and geographical regions, needs to be conducted.

The results show no or very weak relationships between predictors and criterion for the participants with migration background. Overt prejudices and xenophobia are not related to the social identity of participants with migration background. In contrast, there is a significant, yet weak, effect with regard to covert prejudices. As Entorf and Lauk (2008) showed, effects of prejudice and group comparison appear for pupils with and without migration background. Against our assumption, it seems that participants with migration background do not openly state their aversion towards other cultures (overt prejudices), although they still harbor them to some degree. It is to note that with 133 participants, the sample of participants with migration background was relatively small. Further investigations with bigger sample sizes are necessary to improve the external validity. These should also include prejudices against different groups and not only refugees.

The main effects of the variables social identity, cultural intelligence, and acculturation strategies on the different types of prejudices were anticipated and found. Higher identification with the ingroup (higher levels of social identity) predicted higher levels of all prejudice types. High levels of cultural intelligence and integration strategies, in contrast, predicted lower prejudices. This supports the results of Bello (2017), who showed the importance of open-mindedness towards intercultural interactions for the reduction of prejudice rather than economic factors. As a logical consequence, interventions that reduce ingroup thinking and facilitate cultural intelligence and more open acculturation strategies could be used to reduce prejudice. Genkova and Kaune (2015) emphasizes that the shift to a broader social identity might lead to less prejudice. However, there is a lack of evaluations for respective measures, even though the approach is not new. Still, there is broad evidence that intercultural competence is strongly linked to less prejudice, even though there are contradictory results regarding the causal order (Genkova \& Kaune, 2015). Anyways, in order to support positive intergroup relations on a societal level, interventions might focus on these aspects.

Another focus of this work was on a possible moderation effect of contact with refugees. It became apparent that contact quantity and contact quality significantly influence the relationship between acculturation strategies and prejudices. No difference was observed when acculturation strategy and contact quality and quantity were high. Hence, if individuals already followed strategies that are beneficial for accepting other cultures such as integration strategies, further contact did not contribute to less prejudice. When the value for acculturation strategies is low, however, 
and prejudices are high, high contact frequencies and positive experiences with the contact can reduce such prejudice.

Contact quantity had no direct effect on xenophobia. Nevertheless, there was a significant interaction effect, which showed that contact quantity contributes to less xenophobia only if the acculturation strategy is high. However, contact quantity has a direct effect on overt and covert prejudices. No further significant effects could be obtained. It is possible that covert prejudices are deeper entrenched in the consciousness and therefore harder to change. In that case, high contact frequencies might lead to the reduction of covert prejudices, yet positive contact that happens occasionally does not (Ramiah \& Hewstone, 2013). As this study cannot solve this issue sufficiently, future research should examine the interaction of contact quality and quantity probably by the application of second-order moderation models.

Moreover, moderation effects involving the identification with the ingroup (social identity) could be observed. This effect, however, could only be observed for the participants without migration background (German students) and the moderator variable contact quality. It was demonstrated that even if identification with the ingroup remains very high and prejudices, confirming $\mathrm{H} 1$, are rather strongly developed, positive contact with refugees reduced prejudices. This indicates that the negative influence of a strongly developed social identity is reduced through contact quality, which is in line with prior research on the contact hypothesis (e.g., Dixon et al., 2010). Contrary to the acculturation strategy values, whereby no difference could be observed between high and low manifestation, it became visible for the social identity that for low as well as high manifestation of this variable, the contact quality could reduce prejudices.

Yet, no moderation effect of contact quantity nor quality concerning social identity on covert prejudices could be found. However, the acculturation strategy and the contact quantity influenced covert prejudice. This might refer to the different connotations of overt and covert prejudice and xenophobia. While overt prejudice and xenophobia are more strongly related to an explicit devaluation of the outgroup, covert prejudice might more strongly relate to fear (Stephan and Stephan, 2000). However, as those aspects are very closely related, further studies should investigate them in more detail with experimental designs in order to generate unambiguous results. Findings like these imply that even individuals who follow a more open and integrative approach do not necessarily have less or more covert prejudices than participants that subscribe to separation more. This is important to keep in mind as also covert prejudice can hinder cross-cultural interactions and predict discrimination (Chin, 2004).

The moderation effect is not present with regard to cultural intelligence. Reasons for this need to be further investigated as well. It is likely that cultural intelligence as a construct is quite robust and its effect is not easily influenced by other factors. If this ought to be true, fostering cultural intelligence would be a reliable method to reduce prejudices regardless of the circumstances. Additionally, the model with ethnic identity as a predictor was not significant. The generally low relationships between this variable and prejudices need to be considered. It seems plausible that the scale multigroup ethnic identity measure is not a suitable assessment tool to 
examine the relationship. On the contrary, it is possible that cultural heritage (ethnic identity) itself does not determine how we see others but that rather the socially developed identity and its accompanied sense of belonging (social identity) does.

Finally, a combined effect of the variables social identity, cultural intelligence, and acculturation strategies was found. Together, those variables can predict the development of prejudices and explain a major part of its variance. Obviously, the three variables as predisposition influence the attitudes towards refugees and through changes in their manifestation influence the expression of prejudices. One needs to take into consideration that ethnic identity as a single variable was not a significant predictor for overt prejudices, neither for xenophobia, but social identity was significant. It stands to reason that one's own ethnicity is not responsible for the development of prejudices, but the feeling towards the ingroup (social identity) is of importance. Therefore, this work contributes to the thoughts of Jones (2002), who saw the source of prejudice in the social identification process.

\section{Limitations}

Through the multitude of constructs, many factors are included, which cannot be investigated thoroughly, given the limited resources available for this study. The constructs were measured with several subscales, respectively, which enable to get a differentiated view on the relationships. However, this makes the survey quite extensive. Through the multitude of variables and accompanied subscales, many subhypotheses were necessary, which scatter the main study and hinder the endeavor to highlight meaningful connections and reciprocities as a whole. For this matter, future research could scrutinize less constructs more differentially or investigate them in a scope of a more extensive work that addresses all variables in more detail. Furthermore, regarding the content of the questionnaire, some participants gave critical feedback. It was often stated that the term ethnicity was not further defined. Many participants did not have a concept of this term, which refers to the item to which ethnic group do you allocate yourself? Moreover, further studies should try to differentiate between first- and second-generation migrants. While it was not the goal of this study to point out differences between first- and second-generation migrants, there are theoretical reasons to put them together, and the study was already quite extensive; we did not differentiate them. However, further studies should address this issue more differentiated. The study at hand did not consider the perceived size of the outgroup as a potential moderator of the relationship between ethnic identification and prejudices, as considering the contradictory results on the role of outgroup size (e.g., Laurence \& Bentley, 2018; Schneider, 2007) would exceed the scope of this text. Future studies should take this relationship into account in order to explain the relationship between identity and prejudices more deeply. The online survey design does not allow statements on the response rate and representativeness of the results provided. However, the survey was distributed in various campusspecific social media groups all over Germany, which is an indicator that the sample provides at least implications for generalized assumptions. 


\section{Practical Implications}

Up to this date, integration has proven to be a successful model to bring benefits to the economy and society (Genkova \& Kaune, 2015). The success of integration depends, as stated in the beginning, on different factors. Behaviors and attitudes of individuals towards other cultures, different acculturation strategies, different social identities, and different degrees of cultural intelligence all play a role for the dynamic interplay between individuals from different cultural backgrounds. These dynamic processes are visible at internationally orientated universities, where contact between students with different cultural backgrounds is part of the concept.

Social identity, the degree of identification with the ingroup, has been proven an important variable concerning the manifestation of prejudices. The development of a shared identity in the sense of identifying with a superordinate group that includes people with different heritages has a positive relationship with less prejudices. This could be promoted, e.g., through projects with refugees or projects and partnerships with international universities, which bring students from different nations together and let them work for a shared goal. In the field of social psychology, it has already been proven that the relationship towards other groups depends on competition (Aronson et al., 2008). If distinct groups are directed towards a common goal, differences are not emphasized but commonalities are highlighted. At the same time, cooperation projects facilitate aspects of intercultural competences, making the participants more capable to cooperate in future encounters. In many studies, it has already been shown that stays abroad are related to a positive development of this construct (Stewart et al., 2014). Such meetings should be accompanied by pre- and post-courses with the topic of cultural intelligence and social identity. Knowledge about psychological processes during group formation and meetings with unfamiliar cultures as well as viewing respective processes on a meta level can enable students to critically reflect on their behavior and their thoughts in such situations (Bolten, 2007). While we raised the study at hand, it became evident that the extent of contact between students and refugees was very low in the obtained sample, which gives food for thought. Even if contact can compensate for negative influences of other variables only to a limited degree, contact programs have demonstrated to be one of the most successful approaches for the reduction of prejudice (Bolten, 2007).

Foresightedly, measures like this indirectly facilitate the integration of refugees at the work place and at educational institutions. Students of today are human resources managers of tomorrow. Low prejudices and competences regarding the handling of multiculturalism support long-term cooperation, and a fair personnel choice are all premises to successfully cooperate in a globalized world. As indicated by the academic work at hand, influences of individual and interpersonal factors can be interpreted meaningfully in order to foster cooperation in a multicultural society.

Funding Open Access funding enabled and organized by Projekt DEAL.

Open Access This article is licensed under a Creative Commons Attribution 4.0 International License, which permits use, sharing, adaptation, distribution and reproduction in any medium or format, as long as you give appropriate credit to the original author(s) and the source, provide a link to the Creative 
Commons licence, and indicate if changes were made. The images or other third party material in this article are included in the article's Creative Commons licence, unless indicated otherwise in a credit line to the material. If material is not included in the article's Creative Commons licence and your intended use is not permitted by statutory regulation or exceeds the permitted use, you will need to obtain permission directly from the copyright holder. To view a copy of this licence, visit http://creativecommons.org/ licenses/by/4.0/.

\section{References}

Allport, G. (1954). The nature of prejudice. Reading: Addison-Wesley Publishing Company

Aronson, E., Wilson, T., \& Akert, R. (2008). Sozialpsychologie. Pearson Studium.

Badea, C., Iyer, A., \& Aebische, V. (2018). National identification, endorsement of acculturation ideologies and prejudice: The impact of the perceived threat of immigration. International Review of Social Psychology, 31(1), 1-10.

Bello, V. (2017). Interculturalism as a new framework to reduce prejudice in times of crisis in European countries. International Migration, 55(2), 23-38.

Berry, J., \& Sam, D. (1997). Acculturation and adaptation. In J. W. Berry, M. H. Segall, \& C. Kagitcibasi Eds., Handbook of crosscultural psychology: Social behavior and applications Vol. 3, 2nd ed. pp. 291-326. Allyn \& Bacon

Bolten, J. (2007). Was heißt „Interkulturelle Kompetenz?“ Perspektiven für die internationale Personalentwicklung. In: V. Künzer \& J. Berninghausen Hrsg.: Wirtschaft als interkulturelle Herausforderung pp. 21-42. Frankfurt am Main

Chin, J. L. (Ed.). (2004). The psychology of prejudice and discrimination. Praeger.

Deardorff, D. (2006). Policy Paper zur Interkulturellen Kompetenz. Bertelsmann Stiftung

Dixon, J., Tropp, L. R., Durrheim, K., \& Tredoux, C. (2010). "Let them eat harmony" prejudice-reduction strategies and attitudes of historically disadvantaged groups. Current Directions in Psychological Science, 19(2), 76-80.

Dovidio, J., Hewstone, M., Glick, P., \& Esses, V. (2010). The SAGE handbook of prejudice, stereotyping and discrimination. Sage.

Earley, P., \& Mosakowski, E. (2004). Cultural intelligence. Harvard Business Review, 82(10), 139-146.

Entorf, H., \& Lauk, M. (2008). Peer effects, social multipliers and migrants at school: An international comparison. Journal of Ethnic and Migration Studies, 34(4), 633-654.

European Social Survey (2014). ESS7 - Documentation report. Retrieved from: https://www.europeanso cialsurvey.org/docs/round7/survey/ESS7_data_documentation_report_e03_1.pdf. Accessed 22 Jul 2021

Genkova, P., \& Kaune, K. (2015). Erfolgreich und zufrieden bei Auslandsentsendungen - der Einfluss von Persönlichkeitsdispositionen auf das subjektive Erfolgserleben. Wirtschaftspsychologie, 18(2), 73-82.

Hall, S. (2003). The question of cultural identity. In S. Hall, D. Held, D. Hubert, \& K. Thompson (Eds.), An introduction to modern societies (pp. 595-629). Blackwell publishers.

Hayes, A. F., \& Cai, L. (2007). Using heteroscedasticity-consistent standard error estimators in OLS regression: An introduction and software implementation. Behavior Research Methods, 39, 709-722.

Hendriks, M., \& Burger, M. J. (2020). Unsuccessful subjective well-being assimilation among immigrants: The role of faltering perceptions of the host society. Journal of Happiness Studies, 21(1), 1985-2006. https://doi.org/10.1007/s10902-019-00164-0

Islam, M. R., \& Hewstone, M. (1993). Dimensions of contact as predictors of intergroup anxiety, perceived out-group variability, and out-group attitude: An integrative model. Personality and Social Psychology Bulletin, 19, 700-710.

Jones, M. (2002). Social psychology of prejudice. Prentice-Hall Inc.

Kemper, T. (2010). Migrationshintergrund - Eine Frage der Definition. Die Deutsche Schule, 102(4), $315-326$. 
Laurence, J., \& Bentley, L. (2018). Countervailing contact: Community ethnic diversity, anti-immigrant attitudes and mediating pathways of positive and negative inter-ethnic contact in European societies. Social Science Research, 69, 83-110.

Lynch, K., \& Kalaitzake, M. (2020). Affective and calculative solidarity: The impact of individualism and neoliberal capitalism. European Journal of Social Theory, 23(2), 238-257.

Miles, E., \& Crisp, R. J. (2014). A meta-analytic test of the imagined contact hypothesis. Group Processes \& Intergroup Relations., 17, 3-26. https://doi.org/10.1177/1368430212470172

Pettigrew, T. F., \& Meertens, R. (1995). Subtle and blatant prejudice in Western Europe. European Journal of Social Psychology, 2(5), 57-75.

Pettigrew, T. F., \& Tropp, L. (2006). A meta-analytic test of intergroup contact theory. Journal of Personality and Social Psychology, 90(5), 751-783.

Phinney, J. (1992). The multigroup ethnic identity measure. Journal of Adolescent Research, 7(2), $156-176$.

Pratt, M. (2001). Social identity dynamics in modern organizations: An organizational psychology/ organizational behavior perspective. In M. Hogg \& D. Terry (Eds.), Social identity processes in organizational contexts (pp. 13-30). Psychology Press.

Ramiah, A., \& Hewstone, M. (2013). Intergroup contact as a tool for reducing, resolving, and preventing intergroup conflict. American Psychologist, 68(7), 527-542.

Schneider, S. L. (2007). Anti-immigrant attitudes in Europe: Outgroup size and perceived ethnic threat. European Sociological Review, 24(1), 53-67. https://doi.org/10.1093/esr/jcm034

Schwartz, S., Montgomery, M., \& Briones, E. (2006). The role of identity in acculturation among immigrant people: Theoretical propositions, empirical questions, and applied recommendations. Human Development, 49(1), 1-30.

Simon, B., \& Trötschel, R. (2007). Das Selbst und die soziale Identität. In K. Jonas, W. Stroebe \& M. Hewstone Hrsg., Sozialpsychologie. Springer

Stephan, W., \& G., Diaz-Loving, R., \& Duran, A. . (2000). Integrated threat theory and intercultural attitudes: Mexico and the United States. Journal of Cross-Cultural Psychology, 3(1), 240-249.

Stewart, A. C., Wilson, C. E., \& Miles, A. K. (2014). Developing ethically \& culturally-intelligent leaders through international service experiences. Journal of Leadership, Accountability and Ethics, 11(2), $115-127$.

Tajfel, H., \& Turner, J. C. (1986). The social identity theory of intergroup behavior. In S. Worchel \& W. G. Austin (Eds.), Psychology of intergroup relationships (pp. 7-24). Nelson-Hall.

Van Dick, R., Wagner, U., Adams, C., \& Petzel, T. (1997). Einstellungen zur Akkulturation: Erste Evaluation eines Fragebogens an sechs deutschen Stichproben. Gruppendynamik, 2(81), 83-92.

Van Dyne, L., Ang, S., \& Koh, C. (2008). Development and validation of the CQS: The cultural intelligence scale. In S. Ang, \& L. Van Dyne, Eds., Handbook on cultural intelligence: Theory, measurement and applications pp. 16-38. Sharpe

Verkuyten, M., \& Zaremba, K. (2005). Interethnic Relationships in a changing political context. Social Psychology Quarterly, 6(84), 375-386.

Wetzels, P., Gabriel, U., \& Pfeiffer, C. (1998). Ausländerfeindlichkeit. In R. Strobl \& W. Kuehnel Hrsg., Dazugehörig und ausgegrenzt. Analysen zu Integrationschancen junger Aussiedler. Weinheim

Wessendorf, S., \& Phillimore, J. (2019). New migrants' social integration, embedding and emplacement in superdiverse contexts. Sociology, 53(1), 123-138.

Williams, M. H. (2010). Can leopards change their spots? Between xenophobia and trans-ethnic populism among West European far right parties. Nationalism and Ethnic Politics, 16(1), 111-134.

Publisher's Note Springer Nature remains neutral with regard to jurisdictional claims in published maps and institutional affiliations. 